
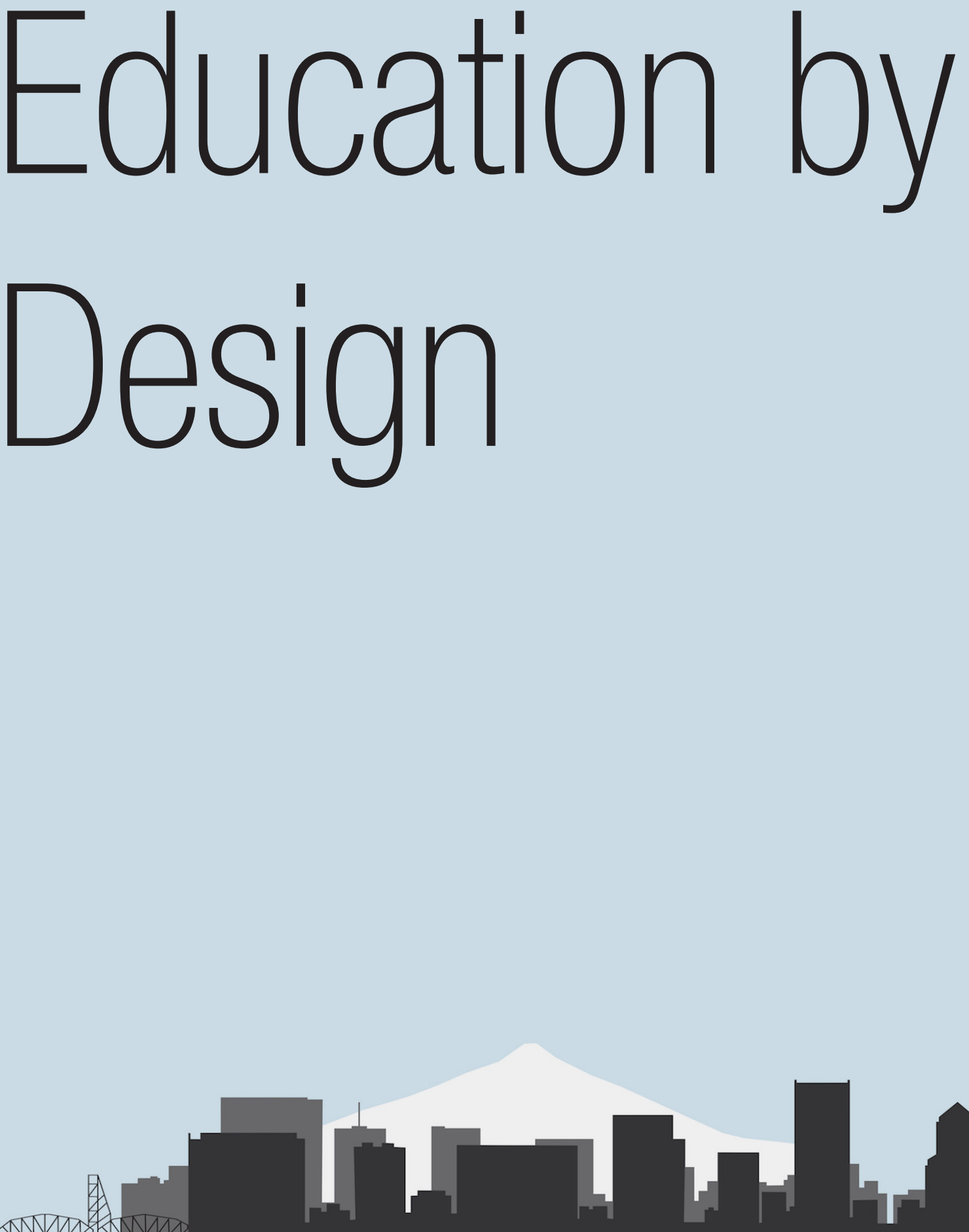

2019 Reynolds Symposium: Education by Design October 18-20, 2019 


\section{Organizing Committee:}

[co-organizers]

Professor Alison Kwok, Ph.D, FAIA, University of Oregon

Emeritus Professor John Reynolds, FAIA, University of Oregon

\section{[Symposium coordinator]}

Isabel Rivera, Ph.D., University of Oregon

Professor Walter Grondzik, P.E., Ball State University

Professor Bruce Haglund, AIA Assoc., University of Idaho

Assistant Professor Emily McGlohn, AIA, Auburn University

Associate Professor Ulrike Passe, lowa State University

Assistant Professor Siobhan Rockcastle, Ph.D., University of Oregon

Sharon Refvem, FAIA, LEED Fellow, Senior Associate and Director, Sustainability Resource Group, Hawley Peterson Snyder 


\title{
Simulating Design Integration in an Architecture Studio Setting
}

\author{
Tom Collins, PhD, AIA, LEED AP \\ Assistant Professor \\ Ball State University \\ Muncie, Indiana \\ tdcollins@bsu.edu
}

\author{
Walter T. Grondzik, PE \\ Professor \\ Ball State University \\ Muncie, Indiana \\ wtgrondzik@bsu.edu
}

\begin{abstract}
Design integration brings discrete elements of the design together early and often to optimize performance outcomes, achieve greater efficiencies, and identify synergies. In practice, design integration often involves getting consultants, clients, and construction managers into the same room to inform and strengthen decision-making. As such, integrated design is the emerging gold standard of building design delivery and an approach that $\mathrm{NAAB}$ now requires accredited architecture programs to incorporate into curricula. However, architecture programs, as silos within their institutions, typically do not have ready access to diverse stakeholders and team members with specialized disciplinary expertise as seen in practice. Thus, the problem facing many architecture programs is how to simulate a "real-life" integrated design process in ways that prepare students for professional careers; require them to consider technical and practical considerations; and expose them to the benefits of holistic, integrated design outcomes. The US Department of Energy's Solar Decathlon (SD) Design Challenge (formerly Race to Zero) provides a useful framework for encouraging and supporting architecture, engineering, and construction management students in developing design teams that engage: industry experts for feedback, community partners as clients, and students across departments. This paper describes the challenges associated with simulating integrated design in an architecture studio setting; the beneficial role that the SD Design Challenge plays in establishing a clear framework with specific design and performance criteria to guide students; and the experiences over a three-year period of a graduate-level comprehensive design studio with supporting technical electives in using the competition to encourage integrated design solutions.
\end{abstract}

\section{INTRODUCTION}

Design integration, integrated design, or other associated terms are now commonly used in architectural practice and education to describe conceptual and practical ways of working and designing that differ from traditional modes of working and designing and that aim to produce superior results. Design integration represents a paradigm shift in the design professions and is often touted as the emerging goldstandard because of its focus on enhanced team collaboration and its superior capabilities in addressing complex design challenges. In the same way that terms such as "green design", "sustainability", or "parametric" are commonly used in design discourse, "design integration" is a now a ubiquitous term that can be difficult to define precisely. For the purposes of this paper, "design integration" and "integrated design" will be used interchangeably.

\section{Definitions}

To better understand design integration as an idea and a method, it is instructive to examine some common definitions. The word "design" can be defined as the process of making a plan, sketch, or outline of something that is to be made or built. In the profession of architecture, design is the process by which ideas and practical solutions to space needs are clearly described and documented. The word "integration" can be defined as the act of combining things into a new holistic thing (Green Building Alliance 2019). By themselves, the definitions of these words do not adequately describe why design integration is innovative or better. After all, architects have always combined or brought together ideas and considerations to inform or guide the design and layout of buildings. 
Several technical definitions are, perhaps, more helpful. One posits that "an integrated design process interlaces the multiple disciplines that inform a building. A series of steps can provide an orderly flow to this dialogue, and the full and constructive participation of all members of the design and delivery team will ensure the best results" (WBDG 2016). Emphasis is placed on the connections and collaboration between different disciplines working on a design project to ensure improved results. The Green Building Alliance suggests that this is a "common definition" for design integration predicated on improved working relationships between team members. However, they also suggest an "enhanced definition" predicated on teams working on or around four specific areas of optimization (climate, use, overall building design, and environmental systems) to find synergies across disciplines that allow for better analysis of alternative strategies and benefit design decision making (Green Building Alliance 2019). One final addition to these definitions is necessary; design integration emphasizes design team member involvement early and often to achieve the most effective synergies. These synergistic opportunities often allow integrated design teams to better address complex issues including, but not limited to, building performance, sustainability, climate change concerns, and durability.

The National Architectural Accrediting Board (NAAB) "develops and maintains a system of accreditation in professional architectural education." They highlight integrated design in the criteria they establish for accredited architecture programs and require that programs demonstrate that students "have the ability to synthesize a wide range of variables into an integrated design solution" (NAAB 2015). The emphasis here is on addressing a range of variables in ways that produce an improved, holistic outcome.

In addition to defining what design integration is, it is also helpful to describe what it isn't. Traditional practice is predicated on disciplinary silos in which architects work quasi-independently from engineers or other consultants, construction managers, builders, etc. This design process involves various disciplines when - and only when - they are absolutely needed in the sequential design process. For example, HVAC systems may be considered a technical consideration that is addressed later in the process once the program and space planning is finalized. This scenario means that engineers will likely not be involved during crucial conceptual development or schematic design. Synergies between spatial layouts and systems components, for example, may not be included in the final design and result in missed opportunities for optimization. Design integration aims to avoid such scenarios.

\section{Integrated Practice}

Design integration is rooted in the practice-based complexities of designing and delivering high quality and high-performance buildings. Elvin suggests that six principles underly successful integrated practices, which isn't merely different disciplines working together in the same office. These principles are "adaptability, economy, innovation, learning, direct experience, and continuous process improvement" (Elvin 2010).

Discussion about integrated practice and design seems to suggest that it is the preferred solution and that its application is now common or widespread. However, we should keep in mind that it represents a big shift in the way practices work and do business and, as such, there are barriers that inhibit or prevent firms from successfully applying the concept to their organizations. This is to say that implementing integrated design may be hard, and it has not been easy for practices to adjust to this mode of working and thinking (Elvin 2010). Elvin also describes integrated practice as an area of rapid growth in the profession and one in which previously separate disciplines are "integrated" into one organizational structure. These comprehensive service firms may include architecture, engineering, and construction services. However, traditional modes of professional work-separate disciplines as separate firms-can act as an impediment to the benefits of integrated practice which may include fast tracking, better coordination/communication, and quality control (Ibid).

Several books have been written about integrated practice. Bachman describes the systematic way that integration can bridge gaps between design intentions and technical requirements and demands (2003). Elvin focuses on case studies of integrated practices that use design integration to create more dynamic workplaces, enhance adaptability to changes in practice, and ensure that businesses survive into the future (2007). These publications aim to present the advantages of integrated practice compared with 
status quo practice and to provide strategies or guidelines to help firms shift focus to a new way of working.

\section{INTEGRATED DESIGN \& ARCHITECTURE CURRICULA}

As integrated design grows in popularity within professional practice circles, accredited architecture programs now address this concept and approach in their curricula. What, perhaps, began as certain professionally-oriented programs aiming to better prepare students for the realities of professional work in practice is today included as criteria that accredited programs must address in their courses.

\section{NAAB Student Performance Criteria}

In their 2014 Conditions for Accreditation and 2015 Procedures for Accreditation, NAAB describes the requirements that an accredited architecture program must meet and the process by which a visiting accreditation team evaluates evidence that a program has met the requirements. Of particular interest and importance to programs and evaluators are the NAAB student performance criteria (SPC). These criteria are intended to provide some consistency to student preparation for the profession while also enabling programs to meet these criteria in their own ways through unique curricula. The SPC are divided into four realms, which help to organize expected skills and abilities more clearly: Realm A, Critical Thinking and Representation; Realm B, Building Practices, Technical Skills, and Knowledge; Realm C, Integrated Architectural Solutions; and Realm D, Professional Practice (NAAB 2014, NAAB 2015).

Two realms address design integration specifically. First, Realm B includes "creating building designs with well-integrated systems" and the individual SPC under this realm focus on stages of the design process (e.g., predesign, etc.) as well as technical systems (e.g., structure, HVAC/lighting, materials/assemblies, etc.). Second, Realm C includes two SPC, C.2 and. C.3, which address integrated design and integrated decision-making, especially considerations that involve complex technical aspects and those related to environmental stewardship (NAAB 2014). Thus, design integration is a mandatory requirement for professionally-accredited architecture programs and several SPC provide a clear indication of the value that NAAB sees design integration providing to professional design education.

\section{Precedents within Architecture Programs}

An analysis of the specifics ways in which accredited architecture programs in the United States are addressing NAAB criteria is beyond the scope of this paper. However, an internet search related to design integration and architecture programs suggests that a number of schools are explicitly including the topic in syllabi, program offerings, and prospective student information, etc. Princeton University (2019), University of Illinois (Illinois 2019), and Rensselaer Polytechnic Institute (2019) all offer integrated design studio courses as part of their professional or preprofessional curricula. NJIT offers a course that they call "4D Integration" that is cotaught with a design studio (2019). Some commonalities among these offerings include co-taught seminar or subject-area courses; working with and responding to feedback from "clients" or "consultants" outside the course (often practitioners or community partners); projects developed and documented to a higher level of technical detail and/or including a broader range of technical considerations; and attention to practical issues of design phases, time management, and financial aspects.

There is even evidence of specific programs or offerings related to design integration outside of the accreditation requirements. The University of Idaho offers an MS degree in "integrated design" (M.S. Integrated Architecture and Design 2019) and the University of Texas at Austin has a Center for Integrated Design (CID), which is an interdisciplinary program for undergraduate students (Center for Integrated Design 2019).

The above examples, although not exhaustive by any means, provide evidence that architecture programs are finding ways to incorporate design integration into their curricula to better prepare students for professional practice and to meet accreditation criteria, that they are doing so using a variety of 
approaches, and that there are trends or common themes across these approaches that emphasize synergistic ways of integrating complex considerations into coherent design products.

\section{Barriers to Implementation of Design Integration}

Emergent trends in professional practice combined with professional accreditation criteria have resulted in architecture programs seeking new and improved ways to address design integration through their curricula and courses. There are, however, several significant barriers to addressing design integration in academia that stem from the realities of the college/university setting and the skill level of the students. First, architecture programs are typically not structured like architecture practices in which: there are often specialists that provide disciplinary expertise during design (e.g. engineers or code consultants); there is a defined budget and timeline for the design process; clients or user groups provide requirements or needs to be addressed by the design; and standards, codes, regulations, and predicted performance are critical to compliance and/or $3^{\text {rd }}$ party certifications. Second, the length of the design process in an academic project is shorter in duration (typically 10-16 weeks) than the duration of a typical professional project, which limits the time students have to develop technical details, etc. For example, the typical design studio project often focuses exclusively on conceptual and schematic design. Fewer studio projects get to the design development or contract document phase. Third, opportunities for interdisciplinary collaboration across departments, programs, colleges, etc. are limited by university structures, disciplinary curricula, and availability (or lack of availability) of specific disciplines within an institution (e.g., some universities do not have a college of engineering). In addition, although NAAB requirements demand that students are exposed to issues related to design integration and integrated design decision making, the accreditation requirements include such a large number of SPC that many programs have limited room in their curricula for electives or cross-disciplinary courses. And, lastly, professionals often work collaboratively in teams composed of members possessing certain skills and abilities. In an architecture program, students within a course have a more limited range of skills and abilities that is highly connected to where they are in their program (e.g., a graduate student who has done an internship and completed 4-5 years of course work compared with a $3^{\text {rd }}$ year undergraduate have vastly different skill sets and experience). Because of these and other legitimate reasons, many schools lack a clear roadmap or framework for structuring a design integration curricular experience.

\section{SOLAR DECATHLON DESIGN CHALLENGE AS A FRAMEWORK FOR DESIGN INTEGRATION}

Now in its $7^{\text {th }}$ year, the SD Design Challenge (previously the Race to Zero (RTZ) -is an annual student design competition sponsored by the US Department of Energy (DOE) and the National Renewable Energy Laboratory (NREL). This paper will use SD Design Challenge and RTZ interchangeably. A requirement of the SD Design Challenge is "the effective integration of building science principles and best practice guidelines for the building enclosure and mechanical systems" (USDOE 2018) as a means of preparing the next generation of architects, engineers, construction managers, and other building professionals to solve real-world problems related to net-zero energy design (NREL 2017). The primary goal of the competition is for students to demonstrate that they can achieve the stringent building performance goals of the DOE's Zero Energy Ready Home (ZERH) program (USDOE 1 2019) through integrated design thinking and decision-making. See Table 1 below for detailed requirements of the ZERH program. As such, the SD Design Challenge provides a useful framework for architecture programs to follow to meet $\mathrm{NAAB}$ accreditation criteria and to prepare students for professional practice.

SD Design Challenge is a two-stage competition with entrants submitting draft and then detailed proposals to a jury of industry experts for review and critique. Annually, 40+ teams compete from 34+ colleges and universities in the US, Canada, and abroad (USDOE 2 2019). The competition originally included only residential building typologies including attached housing, single-family urban, singlefamily suburban, and small multi-family. The building types have expanded in recent years to include mixed-use and non-residential building types such as small schools and office buildings (USDOE 2018). This change is one example of the ways in which the USDOE use feedback from the competition teams to refine and enhance the competition in subsequent years. Indeed, each year at the competition event, 
organizers schedule dedicated meeting time with faculty advisors to solicit feedback. Students and faculty also provide feedback through an evaluation form at the conclusion of the event. One core aspect of the competition that has not changed and remains a signature feature of the SD Design Challenge, is that students are highly encouraged to assemble interdisciplinary teams and to engage community and industry partners outside the university in the design process to provide feedback.

Table 1: Zero Energy Ready Home (ZERH) mandatory requirements (USDOE 2019).

\begin{tabular}{|c|c|c|}
\hline Area of Improvement & \multicolumn{2}{|r|}{ Mandatory Requirements } \\
\hline $\begin{array}{l}\text { 1. ENERGY STAR for } \\
\text { Homes Baseline }\end{array}$ & $\square$ & $\begin{array}{l}\text { Certified under ENERGY STAR Qualified Homes Program Version 3, 3.1, or } 3.2 \text { (depending } \\
\text { on state), or under ENERGY STAR Multifamily New Construction program Version } 1.0 \text { or } 1.1 \\
\text { (depending on state) }\end{array}$ \\
\hline \multirow[t]{2}{*}{ 2. Envelope } & & $\begin{array}{l}\text { Fenestration shall meet or exceed ENERGY STAR requirements. See End Note for specific } \\
\text { U, SHGC values, and exceptions. }\end{array}$ \\
\hline & $\square$ & Ceiling, wall, floor, and slab insulation shall meet or exceed 2015 IECC levels \\
\hline \multirow[t]{2}{*}{ 3. Duct System } & & $\begin{array}{l}\text { Duct distribution systems located within the home's thermal and air barrier boundary or an } \\
\text { optimized location to achieve comparable performance. }\end{array}$ \\
\hline & $\square$ & HVAC air handler is located within the home's thermal and air barrier boundary. \\
\hline \multirow[t]{2}{*}{ 4. Water Efficiency } & $\square$ & $\begin{array}{l}\text { Hot water delivery systems (distributed and central) shall meet efficient design requirements } \\
\text { or }\end{array}$ \\
\hline & $\square$ & Water heaters and fixtures shall meet efficiency criteria \\
\hline \multirow{3}{*}{$\begin{array}{l}\text { 5. Lighting \& } \\
\text { Appliances }\end{array}$} & $\square$ & All installed refrigerators, dishwashers, and clothes washers are ENERGY STAR qualified. \\
\hline & & $\begin{array}{l}80 \% \text { of lighting fixtures are ENERGY STAR qualified or ENERGY STAR lamps (bulbs) in } \\
\text { minimum } 80 \% \text { of sockets }\end{array}$ \\
\hline & $\square$ & All installed bathroom ventilation and ceiling fans are ENERGY STAR qualified \\
\hline 6. Indoor Air Quality & $\square$ & Certified under EPA Indoor airPLUS \\
\hline 7. Renewable Ready & $\square$ & Provisions of the DOE Zero Energy Ready Home PV-Ready Checklist are Completed \\
\hline
\end{tabular}

The competition begins in November and ends at a juried event in Denver at NREL in April. A 10-page progress report is submitted in February and a 40+ page final report is submitted in late March/early April. This schedule allows for differences in how teams run the competition (e.g., one semester vs. two semesters). The competition does not require the competition to be run as a course, which also results in differences among the teams (e.g., with lecture classes, design studios, student clubs, independent studies, etc. being used as the academic home for project development). See Figure 1 below for the range or resources and feedback supporting competition teams.

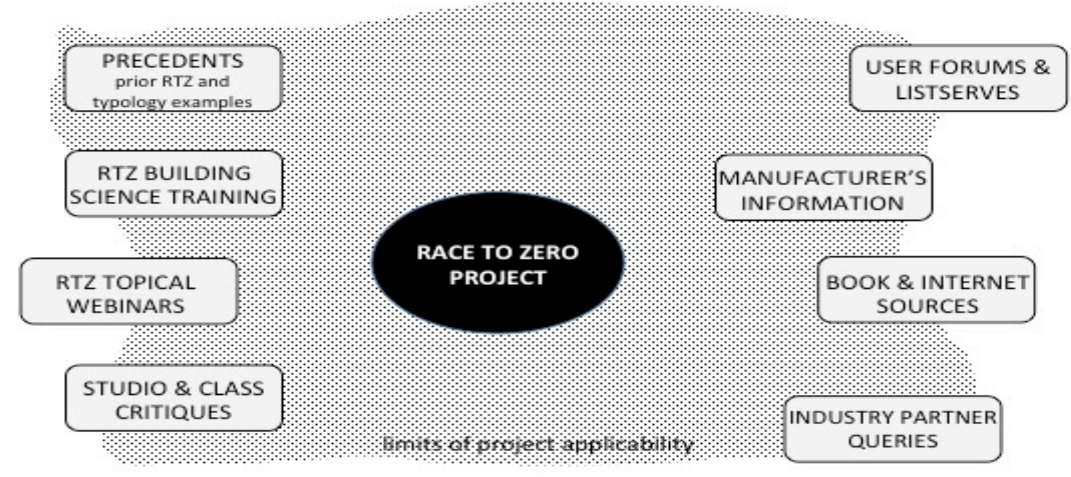

Figure 1: The range of resources and feedback informing SD Design Challenge or RTZ projects is diverse and assists student teams to address complex criteria and to develop the schemes to a higher level of detail. (by authors).

Juries of industry experts evaluate project reports and presentations based on ten criteria or "contests:" energy performance; engineering; financial feasibility and affordability; resilience; architecture; operations; market potential; comfort and environmental quality; innovation; and presentation quality (USDOE 2018). The "contests" evolve from year-to-year and reflects current industry trends (e.g. resilience and operations were new for 2019). These changes require repeat teams to refine their design strategies while responding to a set of criteria that are generally consistent.

Although the competition does not dictate, specify, or scaffold the means, procedures, or processes by 
which the design teams address these technical and performance-based concerns within their projects, DOE does provide significant resources to assist students with these complex concerns. For example, they require 12-hours of online building science training and provide access to software applications. To meet the competition expectations, architecture students need to know and understand far more about the technical and performance aspects of building design than they may be accustomed to engaging in a studio or seminar setting. The competition requirements, framework, and resources assist instructors with helping the students achieve higher levels of detail, address complex criteria, and to seek integrated solutions. However, there is no denying that the competition demands rigor and is a high-pressure experience. Anecdotal evidence gathered from conversations with other faculty and observations of the teams at the event suggest that most teams engage the process with intensity and seriousness.

\section{DESIGN STUDIO EXAMPLE}

\section{Design Studio Course}

Since 2017, a mid-sized Midwestern public architecture program has used the SD Design Challenge as a framework for addressing design integration within its curriculum. A Spring Semester graduate-level comprehensive design studio course (8-9 students typically) functions with two to three teams each competing in a different SD Design Challenge typology category (e.g., Urban Single-family, Attached Housing, etc.). One or two graduate-level elective classes taught by a different instructor act as technical consultants for the studio. There is some overlap between the students taking the elective and the studio, although they are not co-requisites. The mainstay supporting elective course has been focused on energy performance and simulation. Over the years, there have also been electives focused on LEED certification and materials/embodied energy. The content and deliverables for these electives are aligned with the studio and thus the SD Design Challenge milestones. Enlisting participation from a broader range of departments or programs on campus has proved challenging likely due to misalignments between course schedules, a lack of familiarity with the competition, and/or challenges aligning course content. However, several construction management students working with a faculty member from that department provide assistance with the financial analysis and affordability issues and this partnership combined with the seminar-studio arrangement allows for adequate cross-course and cross-disciplinary collaboration opportunities for the teams. Improvements in this area are considered each year.

Industry partners from outside the university provide expertise in specific disciplines such as: green design, housing design, photovoltaic systems, HVAC systems, construction, real-estate trends, etc. These partners interface with the studio in different ways. Approaches include: a series of Friday discussions on campus where the partners present information and answer student questions; partners providing PDF mark-ups of drawings and reports as feedback to the teams; and in-studio charrettes with the partners to generate ideas. The approaches differ based on the proximity of the partners to our off-the-beaten-path campus and/or availability. However, video conferencing, field trips, and a limited number of in-person visits are sufficient in terms of harnessing the expertise of these professionals and soliciting feedback. See Figure 2 below for a photo of student teams working an industry partner.

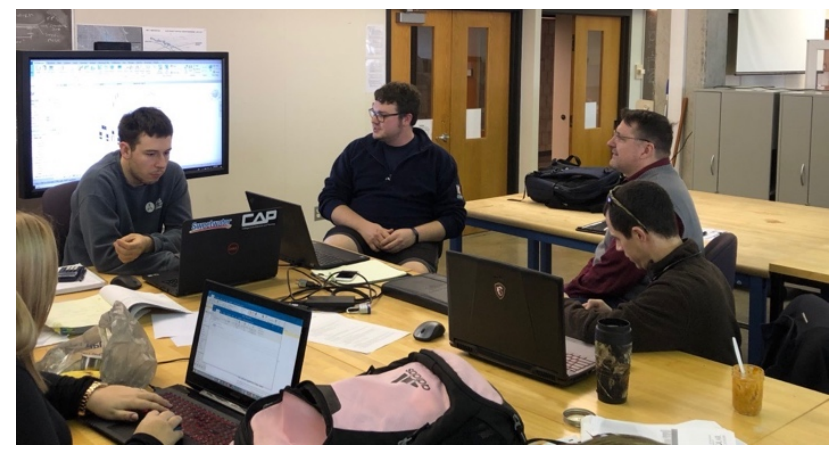

Figure 2: Student team with an industry partner acting as a consultant. Both sides are collaborating to develop a viable solution to a real-world problem, which is very different from a guest lecture, etc. (by authors) 
Local community partners act as clients for the teams. Most recently, these partners have been local nonprofit agencies that focus on affordable housing. They join us for critiques and reviews as well as host groups at their offices or at potential sites. Through experience, we have found that community partners that can provide challenging constraints-whether budgetary, user need-based, regulatory, etc.-provide the best experiences for the student teams to distinguish their projects from others in the competition. See Table 2 below for typical student responses to the competition contests.

Table 2: SD Design Challenge contests and how these concerns are typically addressed in an architecture design studio (by authors).

\begin{tabular}{|c|c|}
\hline SD Design Challenge Contests & Typical architecture studio response \\
\hline Energy performance & $\begin{array}{l}\text { Perhaps the most prescribed of the contests in terms of approach, } \\
\text { benchmarks, and metrics. Responses often highlighting the ways } \\
\text { in which the performance modeling impacted the design } \\
\text { throughout the development and/or going above and beyond to } \\
\text { include analysis from tools/software not required. Associated } \\
\text { elective courses provide assistance and quasi-expertise. }\end{array}$ \\
\hline Engineering & $\begin{array}{l}\text { A less familiar set of criteria for architecture students. However, } \\
\text { high efficiency systems and high performance industry practices } \\
\text { are advocated, which narrow the choices and ease the decision- } \\
\text { making. Industry partners provide assistance with details. }\end{array}$ \\
\hline Financial feasibility \& affordability & $\begin{array}{l}\text { The least familiar set of criteria for architecture students. SD } \\
\text { Design Challenge eases the process with a spreadsheet, but } \\
\text { assistance from industry partners or cross disciplinary } \\
\text { collaboration (e.g. with construction management) is essential. }\end{array}$ \\
\hline Resilience & $\begin{array}{l}\text { Not clearly or sufficiently defined in the SD Design Challenge } \\
\text { guidelines. Students approach this in different ways (e.g. } \\
\text { durability, climate forecasting, natural disaster } \\
\text { avoidance/mitigation, embodied energy/carbon of materials, } \\
\text { etc.). }\end{array}$ \\
\hline Architecture & $\begin{array}{l}\text { Teams struggle with this contest because it appears that } 1 / 10 \\
\text { areas are concerned with architecture. In reality, architectural } \\
\text { concerns permeate many other contests. A typical response is } \\
\text { compelling graphics that highlight the spatial or formal aspects of } \\
\text { the scheme. }\end{array}$ \\
\hline Operations & $\begin{array}{l}\text { Conceptually familiar to students, but a challenge for students to } \\
\text { critically think about users, behavior, controls, maintenance, etc. } \\
\text { This area is not as easily informed by partners. }\end{array}$ \\
\hline Market potential & $\begin{array}{l}\text { Conceptually easy for students to understand, but they lack the } \\
\text { skills or knowledge to effectively analyze the market. Industry } \\
\text { partners are very helpful (e.g. non-profits, real-estate, etc.). }\end{array}$ \\
\hline Comfort \& environmental quality & $\begin{array}{l}\text { Conceptually familiar to students but includes very detailed } \\
\text { requirements and compliance with standards that often fall } \\
\text { outside the purview of partners or elective courses and, as a } \\
\text { result, are often underdeveloped. }\end{array}$ \\
\hline Innovation & $\begin{array}{l}\text { This contest allows teams to demonstrate something unique } \\
\text { about their schemes that goes above and beyond the technical } \\
\text { and performance requirements that are necessary from every } \\
\text { team. The responses vary widely from a unique partnership to } \\
\text { attention to some emerging/intriguing area in design (e.g. social } \\
\text { justice, embodied carbon, etc.). }\end{array}$ \\
\hline Presentation quality & $\begin{array}{l}25 \text { and } 10 \text { minute oral/slide presentations and a graphic poster. } \\
\text { Oral presentations are rehearsed for delivery and transitions } \\
\text { among team members. Slide shows are not the standard design } \\
\text { studio presentation medium, but the graphic poster is familiar } \\
\text { and straightforward for students. }\end{array}$ \\
\hline
\end{tabular}


In addition to community, industry, and cross-disciplinary partnerships, we utilize students who have participated in previous SD Design Challenge Studios to engage the design teams. Sometimes we do this by having them give talks or presentations such as when one of our winning teams from 2017 presented a strategy for effective Power Point slide organization as the teams prepared for the juried event. Often, we enlist students from previous teams to act as jurors at pin-ups and reviews, and these peers provide critical feedback that only a student who has gone through the process would be able to provide. Peculiarly, it is sometimes the case that students from previous years who have, perhaps, not yet fully recovered from the SD Design Challenge process themselves a year or more later are reluctant to engage the process. However, it is almost always evident that our studio students appreciate the support and encouragement of their peers in this challenging endeavor even if they could lean on them a little more for guidance.

\section{Outcomes}

While the above example provides only one of many ways that SD Design Challenge teams may engage issues related to design integration in an academic setting, it nonetheless reveals some inherent advantages and disadvantages that inform course development and may provide guidance to other programs seeking a framework to guide design integration activities.

There are at least four advantages of simulating an integrated design process in an architecture design studio that have emerged from the case study described above. First, students from outside the studio act as experts in a specific area (e.g., energy modeling) and perform analysis and provide feedback to the core teams on issues that they typically have insufficient time or skills to undertake. Through this exchange, the core teams define precise boundaries for investigation and usefulness to the expert consultants. Second, requiring students to work in collaborative teams helps students with integrated decision making, especially when, within teams, members have roles (e.g., envelope or indoor air quality). Third, the strict competition structure and schedule keep students on track and motivated even when the amount of information they are processing and the considerations they are addressing is sometimes overwhelmingat some point, a "failure is not an option" mode of thinking kicks in and keeps teams on task and focused on milestones. And, lastly, forcing students to confront technical issues and complex considerations that they ordinarily would not have time for results in a feeling of empowerment. Even students with weaker technical skills at the onset report at the end of the process that they feel like they learned a lot and that they are more confident in their abilities. Also, although group work is rarely preferred by design students when given an option, most student end the semester with stronger group collaboration skills and group comradery that results from members recognizing the skills and contributions of their teammates.

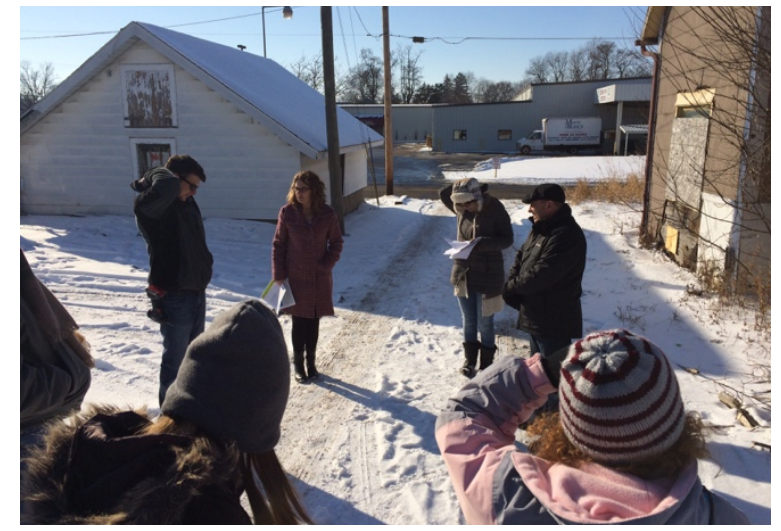

Figure 3: Student team with a community partner acting as a client on a site visit. This type of close collaboration with a party outside the university where students address real-world program and user needs and budgetary constraints is not the norm for design studio projects. (by authors)

While the case study provides clear evidence of the benefits associated with simulating an integrated design process in an architecture design studio, there are at least five challenges worth mentioning that are revealed through the case study example. First, since the students acting as "experts" are learning these skills real-time, this impacts the effectiveness and accuracy of the information they provide to the 
core design teams. Instructors sometimes hear the teams complain that their peer consultants' feedback or analysis isn't sufficient for the technical or performance-based development of their schemes. This sometimes leads the core teams to take some of this work on themselves, which can be redundant, sap available time for other development, and can impeded cross-course collaboration. This issue most often occurs when core teams and expert peer consultants are not communicating effectively or meeting regularly (e.g. when teams revert to a standard model of passing information off from one group to the other). Second, strong community and industry partners can be difficult to find, enlist, and engage in an integrated design studio process. Partners seem quick to say "sure, I'll participate" and then have a hard time knowing how to effectively work with the students to improve their processes and designs. This problem sometimes results from the fact that the projects are student-driven, and students rarely have the skills necessary to inform partners or maintain effective lines of communication. It is important for partners to establish expectations or goals that students can use to guide their process, and sometimes partners ask for deliverables that are different from the materials required by the competition. Third, sometimes the outside experts struggle to engage the technical problems that are in play because the competition encourages teams to pursue solutions that are innovative and/or cutting edge. In our case, this may result from the fact that, in a rustbelt, post-industrial small city, budgets are tight and non-profit organizations are focused on providing basic, simple accommodations for a population with significant housing needs. We acknowledge that large metropolitan areas may offer greater choice when it comes to community and industry partners to work with. It is essential that partners understand up front that the students will employ innovative solutions to meet the intent of the competition. The best partners are ones who are interested in pushing the status quo and/or can provide useful feedback and guidance on emerging technologies and approaches. However, as previously mentioned, real-word constraints related to budgets, construction skills, etc. allow teams to deeply engage local conditions in a specific place. Fourth, in a studio the students do not self-select to enter the competition. This can result in some students who are very motivated to do well and some students who are ambivalent or less interested. It is important to pair ambivalent students with team members who can motivate them and maintain positive team morale. To do this, potential teams need to have frank and honest conversations at the onset about their skills, weaknesses, interests, work habits, etc. Finally, it is easier to coordinate courses working together within a single academic department. When other departments are involved, it can be more difficult to ensure student involvement, meet deadlines, conform with curriculum expectations and accreditation demands, etc. When teams become large, they also become unwieldy, and this interferes with cross-disciplinary collaboration. This is an aspect of our process that we continue to refine.

\section{CONCLUSIONS}

Design integration is an emergent approach to architectural practice predicated on achieving better synergies between team members and enhancing performance outcomes in completed buildings. Architecture programs are now addressing design integration in their curricula to prepare students for innovative trends in practice and to meet $\mathrm{NAAB}$ accreditation requirements that aim to enhance student abilities to integrate complex concerns into a holistic design solution. The DOE's annual SD Design Challenge provides a useful framework for architecture programs and faculty looking for ways to include design integration in their coursework. A graduate-level design studio working in small teams and coordinating work with elective courses and community/industry partners from outside of the university provides one example of a way to address design integration through the SD Design Challenge. This approach, engaged in over several academic years and refined over time, provides evidence of enhanced student collaboration, improved time management/attention to scheduling, and deeper levels of technical development than are ordinarily possible in a semester-long design studio. However, this precedent also suggests that academic structures can impede collaboration and/or require more extensive preparation beforehand to ensure desired success. In addition, there appears to be a marked difference in what students take away from the process based upon their inherent interest in the technical aspects of design. We believe in this approach and will use it again with lessons-learned refinements. 


\section{REFERENCES}

Bachman, Leonard R. Integrated buildings: The systems basis of architecture. Vol. 9. John Wiley \& Sons, 2004.

Elvin, George. "Principles of integrated practice in architecture." Journal of architectural and planning research (2010): 287-300.

Elvin, George. Integrated practice in architecture: mastering design-build, fast-track, and building information modeling. John Wiley \& Sons, 2007.

Green Building Alliance, “Integrated Design,” Green Building Alliance. Accessed June 20, 2019, https://www.go-gba.org/resources/green-building-methods/integrated-design/

Illinois Architecture, "Comprehensive Integrative Design Studio," University of Illinois UrbanaChampaign, accessed June 19, 2019, https://arch.illinois.edu/portfolio/comprehensive-integrativedesign-studio

“M.S. Integrated Architecture and Design,” University of Idaho, accessed June 20, 2019, https://www.uidaho.edu/caa/programs/architecture/ms-integrated-architecture-design/

NAAB. Conditions for Accreditation. National Architectural Accrediting Board. 2014. https://www.naab.org/accreditation/program-resources/current-conditions-and-procedures/

NAAB. Procedures for Accreditation. National Architectural Accrediting Board. 2015. https://www.naab.org/accreditation/program-resources/current-conditions-and-procedures/

NJIT, "University Course Catalog 2018-2019, Master of Architecture and Master of Infrastructure Planning,” New Jersey Institute of Technology, accessed June 19, 2019, https://catalog.njit.edu/graduate/architecture-design/architecture/march-mip/

NREL, 2017 U.S. Department of Energy Race to Zero Student Design Competition Guide, National Renewable Energy Laboratory, 2017.

Princeton University, School of Architecture, “Graduate Courses," Princeton University, accessed June 20, 2019, http://soa.princeton.edu/courses-graduate?field course term tid=541

Rensselaer, “ARCH 6620 - Graduate Architecture Design 4: Integrated Design Studio,” Rensselaer Polytechnic Institute, http://catalog.rpi.edu/preview course nopop.php?catoid=14\&coid=26242

US Department of Energy (USDOE 1), DOE Zero Energy Ready Home National Program Requirements (Rev. 7), May 1, 2019, https://www.energy.gov/sites/prod/files/2019/04/f62/DOE\%20ZERH\%20Specs\%20Rev07.pdf

US Department of Energy (USDOE 2), “2018 Results,” accessed May 24, 2019, https://www.energy.gov/eere/buildings/2018-results

US Department of Energy (USDOE), Solar Decathlon Competition Guide 2019-2020, August 2018.

WBDG, "Engage the Integrated Design Process," National Institute of Building Sciences, last modified October 17, 2016, http://www.wbdg.org/design-objectives/aesthetics/engage-integrated-designprocess 